\title{
Bacillus spp. em bebida industrializada, a base de soja com suco de frutas, em embalagem cartonada
}

\author{
Bacillus spp. in industrialized drink, soy-based with fruit juice, in carton packing
}

\author{
Renato Ventresqui Oliveira ${ }^{1}$; Natalia Castejon Savordelli2; Celso Tadeu Barbosa Santos ${ }^{3}$; \\ Aline Dias Paiva ${ }^{4}$; Afonso Pelli ${ }^{5}$ \\ ${ }^{1}$ Graduando em Ciências Biológicas pela Universidade Paulista, São Paulo, Brasil. \\ Orcid: http://orcid.org/0000-0002-2057-9051. E-mail: ventresqui@gmail.com; \\ ${ }^{2}$ Graduada em Biomedicina pela Universidade Federal do Triângulo Mineiro, Uberaba, Minas Gerais, Brasil. \\ E-mail: n_csavordelli@hotmail.com; \\ ${ }^{3}$ Biólogo. Universidade Federal do Triângulo Mineiro, Uberaba, Minas Gerais, Brasil. \\ E-mail: celsotadeusantos@hotmail.com; \\ ${ }^{4}$ Professora na Universidade Federal do Triângulo Mineiro, Uberaba, Minas Gerais, Brasil. \\ Orcid: http://orcid.org/0000-0003-4234-8892 E-mail: aline.paiva@uftm.edu.br \\ ${ }^{5}$ Professor do Programa de Pós-Graduação em Ciência e Tecnologia Ambiental, Universidade Federal do \\ Triângulo Mineiro, Uberaba, Minas Gerais, Brasil. Orcid: http://orcid.org/0000-0001-8279-2221. \\ E-mail: afonso.pelli@uftm.edu.br
}

\begin{abstract}
RESUMO: Bacillus é um microrganismo comumente encontrado no meio ambiente. Na indústria é considerado um potencial agente de contaminações. O presente trabalho verificou a presença de uma espécie de Bacillus sp. em um suco de frutas a base de soja. O microrganismo foi identificado com base em baterias bioquímicas básicas. Pode-se concluir que os processos de limpeza e higienização realizados nas indústrias podem ser ineficientes para essa cepa em específico.
\end{abstract}

Palavras-chave: segurança alimentar, CIP, bebida à base de soja com suco de laranja.

ABSTRACT: Bacillus is a microorganism commonly found in the environment. In industry is considered a potential agent of contamination. The present work confirmed the presence of a species of Bacillus sp. in a soy-based fruit juice. The microorganism was identified based on basic biochemical batteries. It can be concluded that the cleaning and sanitation processes carried out in the industries may be inefficient for this specific batch strain.

Keywords: food safety, CIP, soy drink with orange juice.

\section{INTRODUÇÃO}

As bebidas à base de soja têm ganhado amplo destaque no mercado brasileiro (SILVA, 2010). Em virtude de propriedades funcionais da soja, com as características sensoriais das frutas, formam bebidas com uma qualidade nutricional aceitável pelo mercado (FARIAS et al., 2009).

A resistência ao meio ácido dos sucos de fruta de laranja é mais comum às leveduras, pois estas possuem particularidades que thes conferem vantagem no crescimento; assim como maior tolerância térmica quando comparadas às bactérias (CORREA-NETO; FARIA, 1999). 
Quando expostos a situações estressantes, como os processos de aquecimento, os microrganismos podem apresentar respostas adaptativas ao estresse que proporcionam a capacidade de sobreviver em condições extremas (JOBIN et al., 2002; SENOUClREZKALLAH; SCHMITT; JOBIN, 2011).

O objetivo deste estudo foi identificar qual microrganismo estava presente, em bebida brasileira, à base de soja com suco de fruta, capaz de sobreviver em condições estressantes de $\mathrm{pH}$ ácido e altas temperaturas.

\section{MÉTODO}

Os isolados bacterianos foram obtidos a partir de uma bebida de soja sabor laranja, comprada em um supermercado convencional, em Uberaba, no Triângulo Mineiro. A embalagem cartonada estava intacta e foi armazenada em temperatura ambiente, em local seco e bem ventilado, conforme recomendação do fabricante. No entanto, a embalagem ficou estufada, sugerindo a formação de gás, mesmo estando dentro do prazo de validade. Apenas uma embalagem apresentava essas características e por essa razão foi adquirida na qualidade de consumidor direto.

A embalagem de um litro foi enviada para o laboratório de Ecologia \& Evolução, do Instituto de Ciências Biológicas e Naturais, da Universidade Federal do Triângulo Mineiro.

Foram avaliados os parâmetros físico-químicos pH, cor e turbidez da amostra.

Para o isolamento do micro-organismo presente na amostra, uma alíquota foi coletada e semeada em Agar-sangue e incubada a $37^{\circ} \mathrm{C}$ por 24 horas. Após o crescimento das colônias, a morfologia celular foi caracterizada através da técnica de coloração de Gram, e a identificação da espécie foi realizada através dos seguintes testes bioquímicos: motilidade em meio semissólido; capacidade de decomposição da tirosina e redução do nitrato a nitrito e crescimento em Agar Bacillus cereus (BRASIL, 2001).

Foi realizado o teste de tubos múltiplos para a quantificação de coliformes totais e termotolerantes através da técnica de número mais que provável. Foi realizado um cultivo da amostra em ágar-sangue por $24 \mathrm{~h}$ a $37^{\circ} \mathrm{C}$ para o isolamento e identificação bacteriana, através de testes bioquímicos convencionais. Todas as análises microbiológicas foram realizadas em triplicatas.

\section{RESULTADOS E DISCUSSÃO}

Com a avaliação dos parâmetros físico-químicos cor e turbidez foi possível observar que se mostraram dentro dos parâmetros preconizados (JAEKEL; RODRIGUES; SILVA, 2010). Já a análise de pH revelou que o suco possuía acidez acima do limite permitido, apresentando valor de 4.04. Esse pH desmotiva o consumo, mas não inviabiliza, altera as propriedades nutricionais e as características sensoriais (JAEKEL; RODRIGUES; SILVA, 2010).

As análises microbiológicas mostraram que não houve contaminação de coliformes totais e coliformes termotolerantes através da técnica dos tubos múltiplos. A partir dos testes bioquímicos, foi possível identificar a espécie como $B$. cereus. Porém, como o grupo é diverso, será necessário a confirmação por meios de identificação mais precisa, em especial através de técnicas de biologia molecular, utilizando o sequenciamento de DNA.

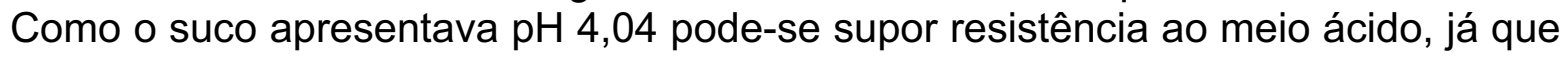
a bactéria se encontrava viável, quer na forma de crescimento ou de endósporo. Mas, para 
que os endósporos sejam produzidos, e a embalagem fique estufada, indicando produção de gases, seria necessário que o crescimento tivesse ocorrido dentro da embalagem, após a pasteurização, como observado por outros autores (SANTOS; MELO; SOUSA, 2019).

Os endósporos bacterianos desempenham importante papel como contaminantes de alimentos. São formas resistentes, aptas a sobreviverem em ambientes com baixos níveis de nutrientes. Algumas doenças transmitidas por alimentos são causadas por endósporos, pois sobrevivem por longo período e são capazes de viver sob ataque químico (CARVALHO et al., 2007; EL-NOUR; HAMMAD, 2013).

Seria razoável avaliar o quão resistente ao $\mathrm{pH}$ ácido a forma vegetativa resiste. Normalmente são testados valores de pH 3, 4 e 5. Para os valores de 4 e 5 podemos supor elevada resistência, o que por si só justifica interesse na variedade em particular.

Caso venha a ser confirmada a contaminação do suco de soja, em embalagem longa vida cartonada, por $B$. cereus, o fato deve ser considerado como relevante. $B$. cereus Frankland e Frankland (1887) é uma bactéria Gram-positiva, beta hemolítica, termofílica e facultativa aeróbia, que pode produzir biofilme. A formação de biofilme poderia ser considerada mecanismo de virulência bacteriana (FAGERLUND et al., 2016). Este é responsável por dois tipos de doenças transmitidas por alimentos, as síndromes eméticas e diarreicas, bem como por infecções não gastrointestinais (KOTIRANTA; LOUNATMAA; HAAPASALO, 2000; BOTTONE, 2010).

As síndromes de intoxicação alimentar de $B$. cereus são causadas pela produção de toxinas distintas. Na síndrome diarreica, os principais fatores de virulência são hemolisina BL (HBL), enterotoxina não-hemolítica (NHE) e citotóxica K (CytK) (GRANUM; LUND, 1997). A HBL é uma toxina de $B$. cereus bem caracterizada que apresenta atividades de permeabilidade hemolítica, citotóxica, dermonecrótica e vascular (BEECHER; MACMILLAN, 1991). Além da síntese de enterotoxina, B. cereus produz uma ampla gama de outros potenciais fatores de virulência, incluindo fosfolipase $\mathrm{C}$, metaloproteases, colagenases e beta-lactamases, embora seu papel em infecções específicas não tenha sido bem estabelecido. Os esporos de $B$. cereus podem sobreviver durante a pasteurização e a maioria dos processos de aquecimento usados na indústria alimentícia; portanto, diferentes produtos alimentícios podem ser contaminados com esta bactéria, incluindo laticínios, carne e sucos de frutas (ARNESEN; FAGERLUND; GRANUM, 2008).

O exame da cultura em um microscópio de luz indicou que $98 \%$ das células bacterianas tinham endósporos. A suspensão de endósporos foi enumerada por meio de plaqueamento em Agar BHI (UFC/mL) e armazenada para posterior confirmação da espécie, através de técnicas moleculares.

A tolerância ao ácido e resistência térmica é uma ferramenta importante para as bactérias sobreviverem em condições estressantes. Em nosso estudo, a espécie de $B$. cereus isolado de um suco comercial, apresentou alta capacidade para sobreviver em altas temperaturas e em ambiente ácido.

A limpeza industrial ou CIP (Clean in place) é baseada em um processo que utiliza hidróxido de sódio e ácido peracético. A alta tolerância de B.cereus encontrado neste suco sugere que, provavelmente, os esporos estavam presentes no tanque de armazenamento de suco (GRUTSCH et al., 2018).

Resistência ao meio ácido foi observada anteriormente em B. cereus (JOBIN et al., 2002). Mecanismos de tolerância podem envolver vias metabólicas relacionadas com a regulação do $\mathrm{pH}$ intracelular, síntese de proteínas e outros mecanismos de reparo intracelular (SENOUCI-REZKALLAH; SCHMITT; JOBIN, 2011). Em um trabalho realizado 
por Browne e Dowds (2001), observou-se que cepas de B. cereus pré-expostas ao pH ácido, apresentaram resistência na fase estacionária de crescimento.

$B$. cereus geralmente prefere o crescimento em $\mathrm{pH}$ neutro, mas quando exposto a $\mathrm{pH}$ baixo, como 4,0 a 5,0, mostra adaptações a este tipo de ambiente. Um mecanismo provavelmente associado à resistência a ácidos é a ação de uma ATPase, que faz a regulação do meio intra e extracelular. Os resultados mostraram que quando $B$. cereus é exposto a situações estressantes (por exemplo, condições ácidas), a ATPase apresenta atividade e expressão mais altas (MAGALHÃES et al., 2003).

A resistência térmica tem sido descrita em vários estudos sobre bactérias que contaminam alimentos (GAILLARD; LEGUERINEL; MAFART, 1998; CARVALHO; VANETTI; MANTOVANI, 2008). Essa resistência térmica está relacionada a mecanismos de sobrevivência ao estresse que aumentam a expressão de proteínas de choque térmico que protegem as células formadoras de endósporos (GEORGOPOULOS; WELCH, 1993). Essa resistência térmica tem sido amplamente estudada, uma vez que processos como pasteurização e Ultra-HighTemperature deveriam matar essas células, mas algumas vezes, em alguns tipos de alimentos a contaminação bacteriana ainda é encontrada (KAMAT; NERKAR; NAIR, 1989; LARSEN; JORGENSEN, 1999).

\section{CONCLUSÕES}

Nossos resultados sugerem que os endósporos de $B$. cereus isolados de bebida à base de soja com suco de laranja são resistentes ao ácido, alta temperatura e pasteurização. Provavelmente estes endósporos estavam presentes no tanque de armazenamento e passaram para a embalagem, juntamente com o suco. Caso a espécie seja confirmada, atenção especial deve ser dada, pois a espécie pode ser tóxica e, em casos raros, levar a óbito.

\section{AGRADECIMENTOS}

Os autores agradecem à Universidade Federal do Triângulo Mineiro pelo apoio financeiro e pelas facilidades concedidas.

\section{REFERÊNCIAS}

ARNESEN, L. P. S.; FAGERLUND, A.; GRANUM, P. E. From soil to gut: Bacillus cereus and its food poisoning toxins. FEMS Microbiology Reviews, v. 32, n. 4, p. 579-606, 2008.

BEECHER, D. J.; MACMILLAN, J. D. Characterization of the Components of Hemolysin BL from Bacillus cereus. Infection and Immunity, v. 59, n. 5, p. 1778-1784,1991.

BOTTONE, E. J. Bacillus cereus, a volatile human pathogen. Clinical Microbiology Reviews, v. 23, n. 2, p. 382-398, 2010.

BRASIL. Ministério da Saúde. Agência Nacional de Vigilância Sanitária. Resolução RDC nº 12, de 2 de janeiro de 2001. Aprova o Regulamento Técnico sobre Padrões Microbiológicos para Alimentos. Diário Oficial da União: seção 1, Brasília, DF, 10 jan. 2001. 


\section{RB}

Revista Brasileira de Ciência, Tecnologia e Inovação

DOI: https://doi.org/10.18554/rbcti.v5i1.3925

BROWNE, N.; DOWDS, B. C. Heat and salt stress in the food pathogen Bacillus cereus. Journal of Applied Microbiology, v. 91, n. 6, p. 1085-1094, 2001.

CARVALHO, A. A. T.; COSTA, E. D.; MANTOVANI, H. C.; VANETTI, M. C. D. Effect of bovicin $\mathrm{HC} 5$ on growth and spore germination of Bacillus cereus and Bacillus thuringiensis isolated from spoiled mango pulp. Journal of Applied Microbiology, v. 102, n. 4, p. 10001009, 2007.

CARVALHO, A. A. T.; VANETTI, M. C. D.; MANTOVANI, H. C. Bovicin HC5 reduces thermal resistance of Alicyclobacillus acidoterrestris in acidic mango pulp. Journal of Applied Microbiology, v. 104, n. 6, p. 1685-1691, 2008.

CORREA-NETO, R. S.; FARIA, J. A. F. Fatores que influem na qualidade do suco de laranja. Ciência e Tecnologia de Alimentos, v. 19, n.1, 1999.

EL-NOUR, S. A.; HAMMAD, A. Inactivation of Bacillus cereus spores in liquid food by combination treatments of heat and irradiation. Food Science and Quality Management, v. 19, p. $31-39,2013$.

FAGERLUND, A.; SMITH, V.; RØHR, A. K.; LINDBÄCK, T.; PARMER, M. P.; ANDERSSON, $\mathrm{K}$. K. et al. Cyclic diguanylate regulation of Bacillus cereus group biofilm formation. Molecular Microbiology, v. 101, n. 3, p. 471-494, 2016.

FARIAS, M. M. A. G.; BERNARDI, M.; SILVA NETO, R.; TAMES, D. R.; SILVEIRA, E. G.; BOTTAN, E. R. Avaliação de propriedades erosivas de bebidas industrializadas acrescidas de soja em sua composição. Pesquisa Brasileira em Odontopediatria e Clínica Integrada, v. 9, n. 3, p. 277-281, 2009.

GAILLARD, S.; LEGUERINEL, I.; MAFART, P. Model for Combined Effects of Temperature, $\mathrm{pH}$ and Water Activity on Thermal Inactivation of Bacillus cereus Spores. Journal of Food Science, v. 63, n. 5, p. 887-889, 1998.

GEORGOPOULOS, C.; WELCH, W. J. Role of the major heat shock proteins as molecular chaperones. Annual review of cell biology, v. 9, p. 601-634, 1993.

GRANUM, P. E.; LUND, T. Bacillus cereus and its food poisoning toxins. FEMS Microbiology Letters, v. 157, n. 2, p. 223-228, 1997.

GRUTSCH, A. A.; NIMMER, P. S.; PITTSLEY, R. H.; MCKILLIP, J. L. Bacillus spp. as Pathogens in the Dairy Industry. In: HOLBAN, A. M.; GRUMEZESCU, A. M. (ed.). Foodborne Diseases: Handbook of Food Bioengineering. Elsevier Inc., 2018. cap. 7, p. 193-211.

JAEKEL, L. Z.; RODRIGUES, R. S.; SILVA, A. P. Avaliação físico-química e sensorial de bebidas com diferentes proporções de extratos de soja e de arroz. Ciência e Tecnologia de Alimentos, v. 30, n. 2, p. 342-348, 2010. 
JOBIN, M. P.; CLAVEL, T.; CARLIN, F.; SCHMITT, P. Acid tolerance response is low-pH and late-stationary growth phase inducible in Bacillus cereus TZ415. International Journal of Food Microbiology, v. 79, n. 1-2, p. 65-73, 2002.

KAMAT, A. S.; NERKAR, D. P.; NAIR, P. M. Bacillus cereus in Some Indian Foods, Incidence and Antibiotic. Heat and Radiation Resistance, v. 10, p. 31-41, 1989.

KOTIRANTA, A.; LOUNATMAA, K.; HAAPASALO, M. Epidemiology and pathogenesis of Bacillus cereus infections. Microbes and Infection, v. 2, n. 2, p. 189-198, 2000.

LARSEN, H. D.; JORGENSEN, K. Growth of Bacillus cereus in pasteurized milk products. InternationalJournalof Food Microbiology, v. 46, p. 173-176, 1999.

MAGALHÃES, P. P.; PAULINO, T. P.; THEDEY JÚNIOR, G.; LARSON, R. E.; CIANCAGLINI, P. A $100 \mathrm{kDa}$ vanadate and lanzoprazole-sensitive ATPase from Streptococcus mutans membrane. Archives of oral biology, v. 48, p. 815-8124, 2003.

SANTOS, I. P.; MELO, T. A.; SOUSA, F. M. O. Análise microbiológica e identificação de adulterantes em leite in natura e pasteurizado comercializado em Jequié-BA. Revista Interscientia, v. 7, n. 1, p. 66-82, 2019.

SENOUCI-REZKALLAH, K.; SCHMITT, P.; JOBIN, M. P. Amino acids improve acid tolerance and internal $\mathrm{pH}$ maintenance in Bacillus cereus ATCC14579 strain. Food Microbiology, v. 28, p. 364-372, 2011.

SILVA, T. A. A. Avaliação Do Potencial Erosivo De Bebidas À Base De Soja. Revista Brasileira de Ciências da Saúde, v. 14, n. 1, p. 109-114, 2010. 